\title{
Natural light in traditional architecture of Iran: lessons to remember
}

\author{
F. Ahani \\ Islamic Azaad University, Fouman \& Shaft Branch, Iran
}

\begin{abstract}
- Climatic function of light

- Psychological function of light

- Aesthetic function of light

- Spiritual and symbolic function of light
\end{abstract}

Taking into consideration natural light as a key factor in visual perception of the world, traditional architects, as skillful hunters of this phenomenon, always utilized it with regard to general principles of Iranian architecture. Notions such as hierarchy, centrality, balance, unity, which all of them are engendered by symbolic aspects of light as the most direct representative of sun, sky, heaven, truth and especially an omnipresent God; Consequently one can observe several elements or structures like fire temples, "Orosi"s (latticed windows), light wells and many others in Iranian architecture which are created to interact with light.

This paper, based upon a holistic approach and a qualitative research methodanalyses the role of natural light in traditional architecture of Iran. The results of this study reveal that light role in traditional architecture of Iran (in both preIslamic and the Islamic period) can be classified in five categories including:

Examining the mentioned roles also implies that most of these applications are yet capable of fulfilling human needs in modern and post modern society, another noticeable fact which makes it necessary to re-examine Iranian traditional architecture and revitalize its considerable achievements.

Keywords: traditional architecture, Iranian, natural lighting, climatic, aesthetics, psychological, symbolic, function. 


\section{Introduction}

As we know, light is a key to human visual perception of the world since a comprehension of matters, colours, patterns and spaces depends upon the light quality and quantity. On the other hand, the multi-dimensional aspects of light function which include psychological and aesthetic roles in addition to climatic and spiritual ones, get several artists and architects such as Luis Kahn, Le Corbusier, etc interested in it.

One of the most famous statement about the light importance is made by Le Corbusier, a well-known pioneer of modern architecture who wrote; "Architecture is masterly, correct and a magnificent play of masses brought together in light" (Le Corbusier [1]).

Similarly, Iranian traditional architects have also learned from their experiences that if they make a good use of environmental light in architecture then they will be capable of transforming the simplest forms and valueless materials to precious elements and decorations. The reason for Iranian architecture being full of light existence is so that one would say traditional buildings wefts are interlaced with light woofs.

Taking into consideration that light role in traditional architecture of Iran has been studied by a wide range of scholars like Ardalan and Bakhtiar [7], Corbin (1977), Ayvazian [10], Stierlin (1969, 1977), etc, it seems that the subject is not a new one, but what makes this paper different from previous ones and reveal its importance is that mentioned researches often were not comprehensive and cover just some aspects of light function. Moreover they didn't propose any classification of them nor a method for its usage in contemporary era. The aim which is followed in this Paper based upon a qualitative research method.

\section{Light and architecture}

Light and water are the main component of Iranian architecture. In central Iran's hot climate, the water from courtyard pools and fountains cools as it decorates. Water cannot only reflect the light and multiply the decorative themes, it can also serve as a means of emphasizing the visual axes. Like the images they mirror, pools of water are immutable, yet constantly changing; fluid and dynamic, yet static [2]. Similarly, windows as the main source of light in traditional buildings are also distributed with regard to the existent geometrical order of the building so that they could intensify them.

In opposition to the monotonous artificial lighting, which is commonplace in contemporary architecture, light existence in Iranian traditional architecture was never thoughtlessly conceived. Since it is just after regulating light intensity and shaping it carefully that architects let it in. The necessity of shaping the light beams is the common aspect of all light director systems in Iranian architecture which often led to the creation of bright geometric forms inside the building which resulted by geometrical logic of forms, sequence and arrangement of the structure openings. 
Examining the lighting systems in traditional architecture of Iran reveals that there were three current methods including;

1- Making use of direct sunlight through limited number of openings.

2-Passing the light through wooden or stone latticed windows which sometime had colourful glasses.

3-Iluminating the interior space through the light reflection off of mirror works, mosaic works or water surface (Vaafi [3]).

Due to the high intensity of sunlight in central Iran, traditional architects often avoid direct light inside the buildings and made use of several components such as porches, wooden or stone latticed windows or roof light wells whose function was to modify the undesirable aspects of sunlight, Fig 1 .

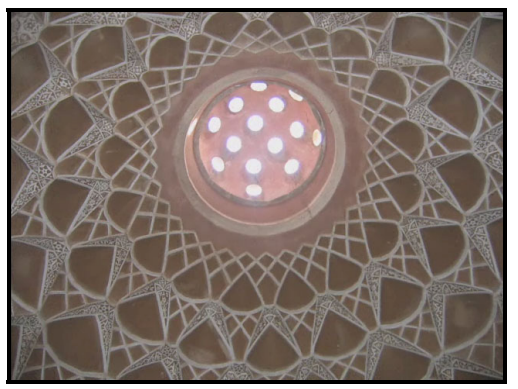

Figure 1: A typical light well in Kashan.

Studying the light role in Iranian traditional architecture approach indicates that its function can be categorized into four main groups:

- climatic function of light

- psychological function of light

- aesthetic function of light

- $\quad$ spiritual and symbolic function of light all of which will be discussed in the following parts.

\subsection{Climatic function of light}

Until the 18th and 19th century (contemporary era), determination of position and orientation of a city fabric and its buildings was carried out based upon a model named Ron. Ron is a rectangle inscribed in a hexagonal whose longitudinal direction shows the best orientation for buildings in order to be energy efficient. Generally there were three current Ron including Rasteh, Kermani and Isfahani each of them which were applicable for special cities (Pirnia [4]). It is noticeable that the Ron orientation itself was determined by issues such as weather condition, wind and specially light direction and intensity in a region which indicates the light influence on the architecture and urban planning in macro scale but it is also an influential factor in micro scale Where 
building spaces in cities like Yazd, Isafhan and Kashan located in hot, arid zones of central Iran are arranged around a central courtyard.

In traditional architecture of Iran, due to the climatic condition of the region, and religious beliefs which resulted in an inward seeking architecture, one can see no opening in the external walls while the inside façade are full of windows facing the courtyard.

Examining the courtyard pattern houses reveals that there are three detectable layers of space located around the main core of light - courtyard - according to the importance of their access to the sun light;

1. The first layer which is just adjacent to the courtyard and includes spaces like

Sedari (bedrooms), Panjdari (guest room), Talaar (living room), etc. Fig 2

2. The second layer containing some spaces of minor importance

3. The third layer which consists of servant spaces like kitchen, water storage, food storage, entrance, etc. (Vaafi [3])

It is noticeable that sometimes in small houses, the second and the third layer were merged into one and due to the lack of accessibility to the courtyard and they were illuminated solely be means of roof light wells. These elements though small in size, often make attractive effects, resulted by light reflection from folded shape surfaces of the sophisticated ornament around them and establish a new order in building geometry which emphasizes its visual axes.
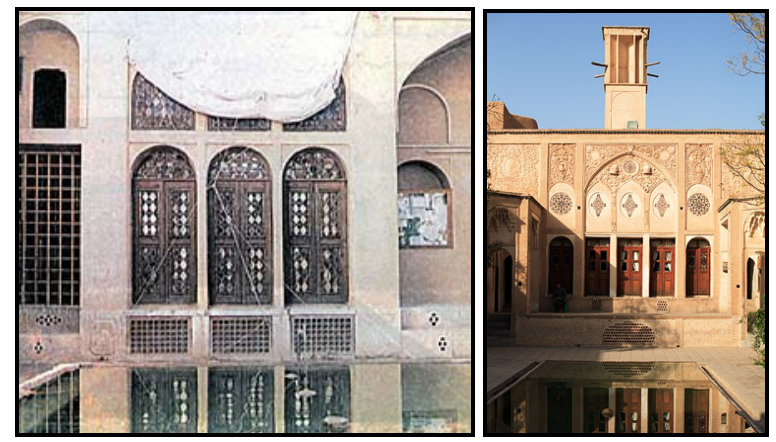

Figure 2: $\quad$ Sedari and Panjdari rooms with latticed windows.

Furthermore, the sunshine angle is influential in size determination of several elements in traditional houses, for example the dept of Sedari and Panjdari rooms and their window's height and width were designed in a way that light could penetrate the interior space as much as it was needed. Moreover the arrangement of living spaces around the courtyard in two different parts named winter and summer zone was based upon the sunshine direction and intensity. Winter zone locating in the northern side of the courtyard contained spaces that faced the south direction hence were suitable places to live in winter. While the summer zone was reversed. Due to such organization in traditional courtyard houses, there was a seasonal and periodical transition in horizontal direction which were influenced by sunshine characteristics. 


\subsection{Psychological function of light (light as the organizer of human visual perception)}

Spatial hierarchy in Iranian architecture are meaningless without light existence In view of light, as a major space component, the overall composition, with adjacent servant spaces, find a particular form of organization, which is centralized and where hierarchies define the general pattern. The order of structure, in which light comes as a containing discovering geometry, commands subsidiary openings, which imposes a disciplined regularity of spaces whilst offering greater complex layers of perception.

Moreover, due to the coherent relation between lighting quality in a space and the importance of its position in the complex, every space in traditional architecture had its own special lighting characteristics which distinguished it from others (Afshar [5]). Consequently the process of visual recognition of space distinctions and their spatial relations would be facilitated for observers and led to what considered by lynch as being influential in giving a feeling of security (Lynch [6]).

This method was also applied in public spaces such as bazaars which were completely inward seeking and didn't have any opening to the outside. Being dependent on such small light wells, the interior space of bazaar's were darker than outside which reminds the observer of one of the most dominant principles of Iranian culture and architecture, which is the distinction between inside and outside characteristics, Figure 3.

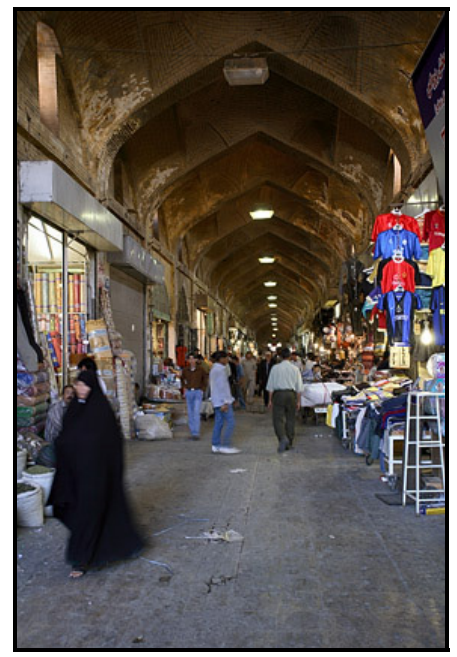

Figure 3: Vakil bazaar.

In the Bazaar, the rhythm and shining angle of light beams while penetrating the interior space and directing the passengers like night stars, compensates the lack of time estimating and orienting capability which is missed due to the lack of relation to the world outside. Moreover, the courtyards placed alternatively in 
the path reduce the monotony of space and prevent a sense of claustrophobia. (Afshar [5]).

Light left a profound influence on the architecture of the bazaar in another way too where its interior structure was emphasized by the obvious difference in the lighting intensity of various parts such as the central path or stores. For example, the lighting method in places like "Timche's" - a square surrounded by some commercial firms - was very sophisticated in comparison to others which refer to their special position in the existent hierarchy.

On the other hand, light can produce qualities like balance, symmetry of centrality, for instance lighting through a light well in the centre of a domed space roof intensifies the centrality of the room. Moreover the oblique radiation of light in such spaces which makes one side brighter than other weakens its symmetrical organization and changes it to a more dynamic one.

\subsection{Symbolic and spiritual function of light}

Studying the history implies that light and fire were sacred to Aryans, the very first inhabitants of Iran; the belief which led to the construction of many fire temples in Iran as the centers for religious ceremonies. At the beginning, the fire temple structure was open to the sky while later it was covered with a domed roof to protect the inside fire from the wind. These sacred structures were designed based upon circle and square geometry - two perpetual shapes which have profound meaning in Iranian beliefs- since square refer to the earth and everything of earthly matters, while the circle is considered a symbol of the heaven and sky, and the combination of them refers to the unity of earth and the heavens (Ardalan and Bakhtiar [7]).

The ascension of humans' mind from the earth to the heaven changed the tendencies toward fire worship to sun worship and fire symbols replaced by sun

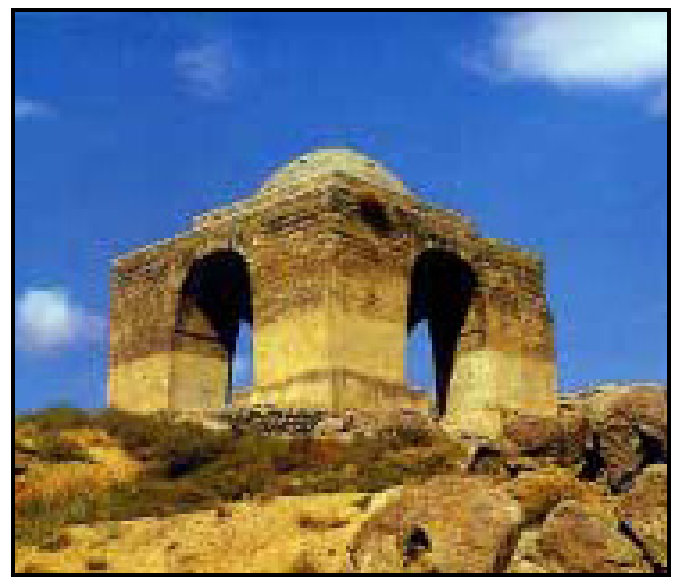

Figure 4: $\quad$ Iranian fire temple. 
ones. The reason for several uses of the word Mitra or Mitreh and its symbol in Avesta and Achaemenid reliefs, Gholizadeh [8]).

Even after the rise of Islam in Iran, light was still considered to be sacred and respectful since it was a powerful symbol of God's essence as is said in the Quran; "god is the light of the earth and the sky. All the lights originate from it. Some evident like sun shine and some hidden .... ." [9]. Therefore Iranians found some aspects in common with the new religion which led to the continuity in their art motifs.

Moreover, the origination of several fundamental concepts of illumination school - A philosophical -Islamic school which was founded by Ebne Sina and Sheikh Suhravardi in the $18^{\text {th }}$ century - such as the unity of existence or disciplines like respecting love, sun, light from previous religions such as Mitraism testifies theses common aspects.

In Iranian architecture, the light metaphor engenders metaphysical connotations, where the Devine is always omnipresent. Light is always a virtue of the sky, of heaven, of truth, of realization, even if brightness is sometimes hidden by shade or darkness. Light and shade are maintained for space perception, while never be in real conflict of meanings. Continuity, passage, the heavenly sphere, stars, centrality, unity are notions and elements of a concept of Islamic architecture, where the environment always remains the impact of the Creator's trace (Ayvazian [10]).

Light, through the succession of sequences bring in life, the symbolism of the supra-natural and the living social connotations of man's passage through earth.

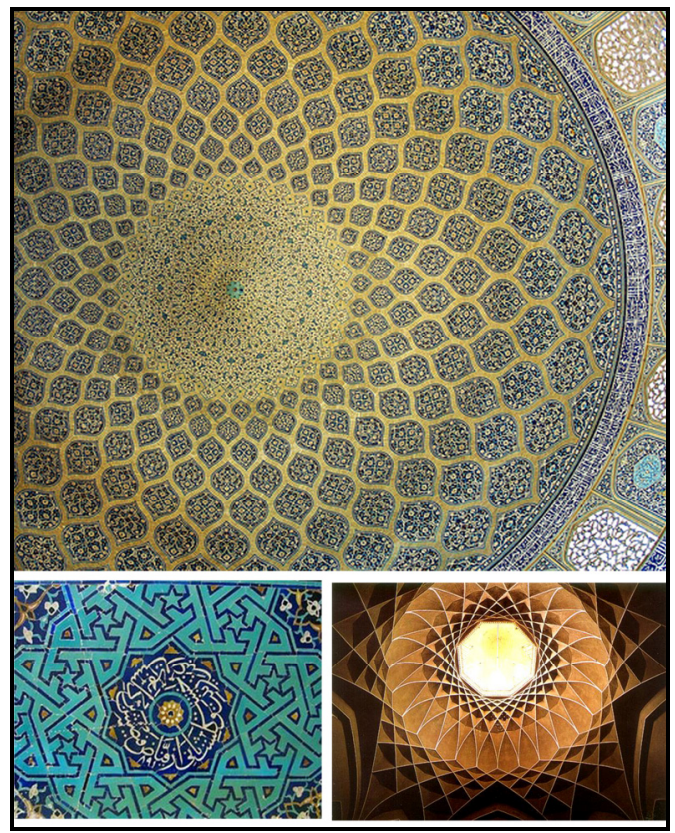

Figure 5: Sun symbol in ornaments called Shamseh. 
Light-space is more than an imaginary space, it comes as a life meaning, a receptacle of human soul and man's activities, illuminating senses to the universal existential principles. A relationship is established with a dependence of man towards heaven, where surfaces, walls and roofs become the symbolic embracing envelop for a world-view made of spiritual values of being. There is always a balance between the inversion of light with the general overall spatial geometry of order, spirit and wisdom.

One of the other religious beliefs which reflect on architecture was intensified by means of light application as was the tendency toward maintaining privacy. As a result of this attitude in traditional residential architecture of Iran, before entering the central courtyard, one would pass through a narrow and windowless, hence dark, walkway called Dallaan. The contrast of the darkness in Dallaan space and intensive sunlight in the courtyard led to the disturbance of a person's eyesight for some minutes in which the female inhabitants of the house could cover themselves with a veil (Memarian [11]).

\subsection{The aesthetic function of light}

\subsubsection{Light as an independent entity}

Light did not just play a complementary role in Iranian traditional architecture and sometimes have its own visual expression. For instance light beams penetrating the interior space through Orosi windows often create remarkable patterns on the wall or the floor which looks like an artistic painting or a precious carpet. Moreover, light sometimes produces bright and dynamic textures inside where its motion doesn't follow the building geometry so led to the transformation of its static order to a dynamic one (Afshar [5]).

On the other hand, shadow as light also has an effect in Iranian architecture since it is a symbol of life. Shady trees are one of heaven's components which is
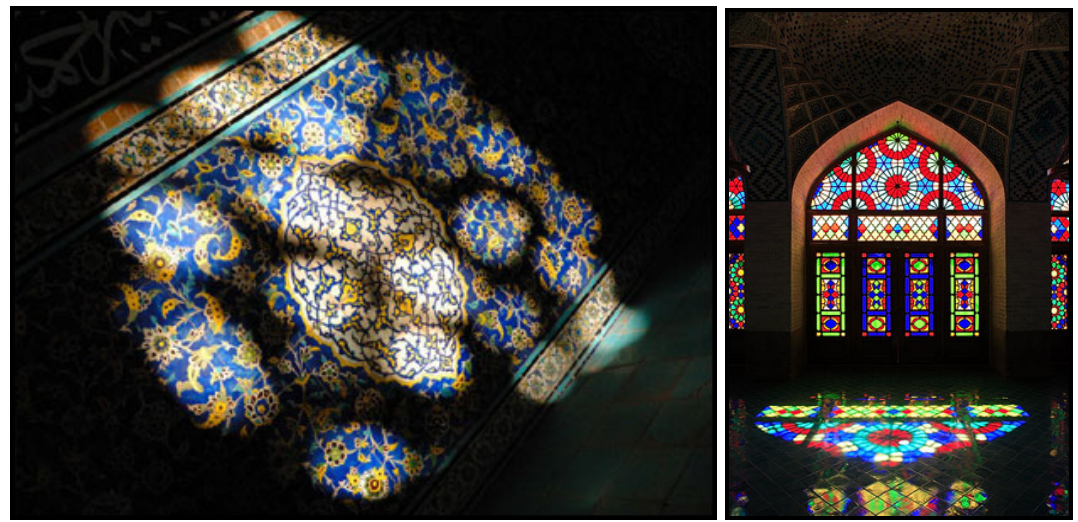

Figure 6: Light; an independent entity. Attractive light effects created by Orosi (right) and latticed (left) windows. 
promised in Islam. Furthermore, in Parsi language being in the shadow of someone refers to being protected by him. Sometimes architectural elements produce such weird shadows which can be considered as independent entities. Moreover, the rhythm of adobe domes and vaults shadows in the desert cities of Iran are so eye-catching that they compensate the visual lack of openings in the buildings' facades.

\subsubsection{Light as a transformer}

Being aware of the high intensity of sunshine in Iran, tradition architects often refracted the light to create aesthetical values. This was carried out by making use of mirror works, mosaic works and any reflective material. Intensifying the magic qualities of Iranian architecture, this method developed its ornaments to a degree of complexity and sophistication previously unknown.

One of these ornaments is named Mugharnass. A honeycomb decoration that reflect and refract light and creates thousands of various lighting effects. While Mugharnass is made of stone, wood or adobes, it is often seems to be an illuminating structure. The reason why many experts believe that Iranian architects were alchemist making gold out of dust [2].
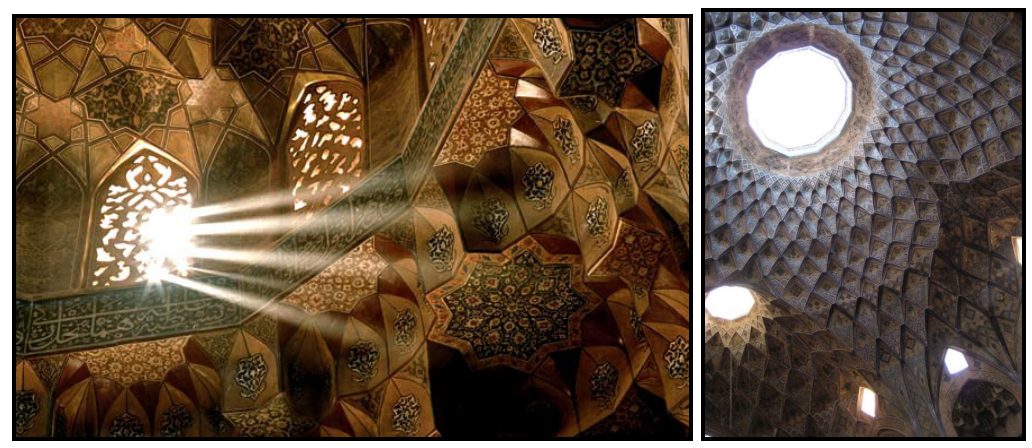

Figure 7: Light as a transformer. The Mugharnass under the dome reflect the light (left: Sheikh Lotfollah mosque), (right: Borujerdiha house).

\subsubsection{Light and ornament}

As mentioned before, due to the intensive sunlight in central Iran which emphasizes the prominence of reliefs, there is no need to emboss decorations in Iranian architecture (Afshar [5]). Moreover, after the rise of Islam in Iran, the creation of sculptural ornaments were prohibited; the reason which led to a remarkable growth in relief works.

Study of these relief motifs reveals that their hierarchy was often intensified by sunlight where main forms produced strong light effects due to their considerable depth while the subordinary and complementary ones created weak shadows. Sometimes light radiation on such surfaces led to the undesirable complexity and a noticeable increase in the visual information level which may disturb a human's perception of the space. Being aware of this problem traditional architects often used monochrome or inconspicuous reliefs as internal 
facade decoration which mediated between the impact of the interior space sophisticated ornaments and ornamentless appearance of building external walls, (Khojastepoor [12]).

Traditional architects even took into consideration the light quality in their colour choice for ornaments. For example since most colours are seen bluish or yellowish under the sunlight in Iran, yellow and blue are frequently used in mosaic works. There is also another reason and that is in these colours' permanence through high resistance against sunlight (Afshar [5]).

It is noticeable that one of the most beautiful architectural elements which was designed based upon aesthetical aspect of light are Ororsis, latticed windows with colourful pieces of glass which creates a spiritual atmosphere by producing attractive light effects inside buildings. Moreover, it is an effective tool to reduce the undesirable intensity of sun light (Pirnia [4]).

\section{Conclusion}

In this paper we discussed the natural light's role in Iranian tradition architecture Based upon the results, the light function in the field of architecture can be categorized in five groups including climatic, aesthetic, symbolic and psychological ones.

Determination of building orientation, the rooms' depth with regard to the sunlight angle and its direction, utilizing several elements like latticed windows to reduce the light intensity and application of light wells on the roof are just a small part of light climatic influence on the architecture.

On the other hand, emphasizing the spatial structure of the building which led to a clear organization of visual perception and leave a good psychological effect on human mind indicate the other aspects of light existence.

Moreover, making use of transformed light (such as the light passed through Orosis), its rhythmic effects or symbolic aspects in architecture refers to its aesthetic function.

Being aware of theses aspects, Iranian traditional architects utilized several outstanding methods of lighting which deserve to be preserved and revitalized while due to the identity crisis and social alienation as a result of multidimensional relation with western countries during $19^{\text {th }}$ century and the consequences of globalization process in the $20^{\text {th }}$ century, most of these precious achievements are going to be forgotten. Nowadays, in a large number of buildings, even in hot arid regions, the external facades are full of windows whose size, position and orientation are determined by architects' taste or temporary fashions and do not have any function but climatic or aesthetic one. Moreover, due to the wide scope of artificial illumination application in contemporary architecture, the lighting quality of interior spaces is often monotonous and static which is undesirable. While, based upon investigations, there are some permanent principles in Iranian tradition architecture which yet are applicable for instance: 
- Determination of size, position and form of openings with regard to the quality and quantity of sunlight and also existent desirable perspectives around the building.

- Application of light in the architecture as a dynamic and aesthetic phenomenon.

- Natural Lighting application for emphasizing spatial structure and relations of a building.

- Creation of virtual and dynamic textures in monotonous surface of the façade, walls and floor.

- Designing facades and its decoration with regard to the intensity of sun light.

- Making use of symbolic aspects of light in order to create a spiritual space in the architecture.

- Organizing the visual information and facilitating the perception process by means of lighting methods.

- Reducing the energy consumption vie the maximum use of natural light

Contemporary architects should understand the essence of these principles and allow modern building technology to be a tool in the expression of them. As writes Martin, "Architects working today can take advantage of opportunities that new materials and mass production techniques offer. They have an opportunity to explore and transform the possibilities of the machine age for the enrichment of architecture in the same way that craftsmen explored the nature of geometrical and arabesque patterns. .." The forms that would evolve from this approach, adds Martin, would have a regional identity, a stylistic evolution and a relevance to the eternal principles of architecture [13].

\section{References}

[1] Le Corbusier, http://www. architecture-lighting. com/lighting quotes. html.

[2] Architecture, Islamic arts and architecture organization, www. salaam. co. uk/themeofthemonth/march02 index. php? $1=5$

[3] Vaafi, M. H., Windows in residential architecture of Isfahan, 9(5), pp131136, 2002.

[4] Pirnia, K., An introduction to Islamic architecture of Iran, Sorooshe Denesh verlag, pp155-156, 2006.

[5] AFshar Naderi, K., Iranian architecture, Aghaah verlag, Tehran, pp10-17, 2003

[6] Lynch, Kevin, The image of the city, MIT press, Cambridge MA, pp37-38, 1960

[7] Ardalan, N. \& Bakhtiar, L., The sense of unity;The Sufi Tradition in Persian architecture, University of Chicago press, pp 58-59, 1973

[8] Gholizadeh, Y, Light in Iranian beliefs and architecture, Abaadi, 7(3), pp54-55, 1997

[9] Qur'an, Nur 24:35

[10] Ayvazian, S., Light in traditional and Islamic architecture of Iran, Architecture and urban planning, 8(2), pp12-38, 2004. also available 
36 Lighting in Engineering, Architecture and the Environment

[11] Memarian, Gh., a study of theoretical foundation of architecture, Soroosh verlag, Tehran, pp 121-122, 2005

[12] Khojastepoor, A., The aesthetics of light in Islamic architecture, architecture and culture, 5(2), pp23, 2009.

[13] Martin, G. The future of Islamic architecture, available online at Http://islamicart. com/main/architecture/future. html 